\title{
The Association Between SYNTAX Score and Long-term Outcomes in Patients With Unstable Angina Pectoris: a Single- center Retrospective Study
}

\author{
Min Xu \\ Beijing Friendship Hospital \\ Hong-Wei Li (D lhw19656@sina.com ) \\ Beijing Friendship Hospital \\ Hui Chen \\ Beijing Friendship Hospital
}

\section{Research Article}

Keywords: Coronary heart disease, Unstable angina pectoris, SYNTAX score, Major adverse cardiovascular events

Posted Date: May 28th, 2021

DOI: https://doi.org/10.21203/rs.3.rs-530077/v1

License: @ (i) This work is licensed under a Creative Commons Attribution 4.0 International License. Read Full License

Version of Record: A version of this preprint was published at BMC Cardiovascular Disorders on April 7th, 2022. See the published version at https://doi.org/10.1186/s12872-022-02604-x. 


\section{Abstract}

Background: SYNTAX Score affects clinical outcomes in early studies, whether SYNTAX Score could predict long-term outcomes in patients with unstable angina pectoris (UAP) in the era of new generation drug-eluting stent was unclear, and differences by SYNTAX Score in long-term outcomes between the medical therapy and percutaneous coronary intervention (PCI) in UAP patients were not well known.

Methods \n this single-center retrospective study, a total of 2,364 patients with UAP from January 2014 to June 2017 at Beijing Friendship Hospital were enrolled. The primary endpoint was a composite of major adverse cardiovascular events (MACE), including all-cause death, cardiac death, nonfatal myocardial infarction (MI) and stroke after at least 2 year from discharge.

Results冈n this study, 1,695 patients had low SYNTAX score (<22) , 432 patients had medium SYNTAX score (22-32), and 237 patients had high SYNTAX score ( $\geq 33)$, and 1,018 received medical therapy, 1,346 patients underwent PCI. Long-term MACE occurred in 95 patients during $3.38 \pm 0.99$ years follow up. Cox multivariate regression analysis showed advanced age, diabetes mellitus, heart failure, chronic kidney disease (CKD) and high SYNTAX score were independent predictors for MACE in the medical therapy group $(P<0.05)$, while, heart failure and CKD were predictors of MACE in PCl group. Compared to medical therapy group, PCI group showed lower MACE and cardiac death in patients with high SYNTAX score $(\geq 33)(7.4 \%$ vs. $16.7 \%, P=0.048 ; 3.7 \%$ vs $14.6 \%, P$ $=0.004)$, but no reduction in patients with low- and medium SYNTAX score.

Conclusions\&High SYNTAX score could predict long-term MACE for UAP patients with medical therapy, but not for patients undergoing PCl. Compared to medical therapy, $\mathrm{PCl}$ could significantly reduced long-term MACE and cardiac death for patients with high SYNTAX score.

\section{Introduction}

In recent decades, coronary heart disease (CHD) remains a major cause of mortality in worldwide, especially in developing countries. The Synergy between Percutaneous Coronary Intervention with TAXus and Cardiac Surgery (SYNTAX) score was a tool to measure the complexity of coronary lesions, and has been recommended for the risk stratification and treatment decision making for untreated left main trunk or three-vessel coronary heart disease (CHD). Previous studies confirmed that higher SYNTAX score was related to the worse short-term and long-term prognosis of patients with $\mathrm{CHD}^{[1-2]}$. However, in the era of new generation drug-eluting and advanced medicine treatment, whether SYNTAX Score could predict long-term MACE in CHD patients undergoing medical therapy or $\mathrm{PCl}$ is unclear.

Moreover, although coronary revascularization can improve the prognosis of medium and high risk patients with unstable angina pectoris (UAP) in early studies ${ }^{[3-7]}$, most risk scoring systems, such as GRACE and TIMI score, include clinical indicators, not considering characteristic of coronary artery disease. Using SYNTAX score to assess differences in long-term outcomes between medical therapy and $\mathrm{PCl}$ have seldom been found. So, we investigated the long-term outcomes in patients with UAP who underwent medical therapy or PCl.

\section{Methods}

\section{Population}

The present research was a single-center, retrospective, observational study. Data came from UAP patients database of Cardiovascular Center Beijing Friendship Hospital Database Bank (CBDBANK), which includes UAP patients treated from January 2014 to June 2017 in the Department of Cardiology, Beijing Friendship Hospital. All eligible patients were more than 18 years old, and had symptoms of angina as well as at least $a \geq 50 \%$ luminal stenosis in vessels $\geq 1.5 \mathrm{~mm}$ confirmed by coronary angiography. UAP was diagnosed according to the criteria of the European Society of Cardiology guidelines ${ }^{[8]}$. Patients were excluded if they had previous percutaneous coronary intervention (PCI) or coronary artery bypass grafting (CABG) which could affect the accuracy of SYNTAX score. Severe anemia, coronary artery bridge, coronary artery spasm, malignant tumor and incomplete information were also exclusion criteria. 
The treatment strategy was decided by physician according to coronary angiography, and coronary flow reserve fraction (FFR) or optical coherence tomography (OCT) or intravascular ultrasound (IVUS) were performed in borderline coronary lesions to decide the treatment. All patients were given secondary prevention medicine during hospitalization and after discharge, and were followed up by telephone regularly. According to the final treatment method, patients were divided into two groups: the medical therapy group or the $\mathrm{PCl}$ group. This research was performed according to guidelines set by the Helsinki Declaration and was approved by the ethics commission of the institutional review board of Beijing Friendship Hospital.

\section{Data Collection}

The following data were retrospectively collected from the CBDBANK: (1) demographic factors and cardiovascular risk factors, including sex, age, family history of CHD, smoking, hypertension, diabetes mellitus, dyslipidemia, stroke, peripheral arterial disease (PAD), heart failure; (2) laboratory data at admission including hemoglobin, and fasting plasma glucose (FPG), serum lipids, serum creatinine, BMI, and left ventricular ejection fraction (LVEF). (3) calculation of SYNTAX score: using the SYNTAX score calculator (available at http://www.syntaxscore.com), two experienced interventional cardiologists retrospectively calculated the SYNTAX score according to the diagnostic angiograms obtained prior to PCl. The total score was calculated by adding up all individual scores for each separate lesion with a stenosis diameter $\geq 50 \%$ in a vessel $\geq 1.5 \mathrm{~mm}$ in diameter by visual assessment. SYNTAX score were categorized as low SYNTAX score ( $\leq 22)$, medium SYNTAX score (23-32) and high SYNTAX score $(\geq 33)$.

\section{Study definitions}

Hypertension was defined as having a previous diagnosis of hypertension or diagnosed in-hospitalization. Diabetes mellitus was having a previous diagnosis of diabetes mellitus or diagnosed in-hospitalization. Dyslipidemia was defined as having a history of hyperlipidemia, or the total cholesterol (TC) $\geq 5.2 \mathrm{mmol} / \mathrm{L}$, or low-density lipoprotein cholesterol (LDL-C) $\geq 3.4 \mathrm{mmol} / \mathrm{L}$, or triglyceride $(T G) \geq 1.7 \mathrm{mmol} / \mathrm{L}$, or high density lipoprotein cholesterol $(\mathrm{HDL}-\mathrm{C})<1.0 \mathrm{mmol} / \mathrm{L}$ on admission. Hyperuricemia was serum uric acid concentration $>420 \mu \mathrm{mol} / \mathrm{L}$ in males and $>360 \mu \mathrm{mol} / \mathrm{L}$ in females ${ }^{[9]}$. Patients who used to smoke or currently smoke were considered to be smokers. Family history of CHD was any immediate family member (parents, siblings) having CHD. Stroke was having a $\geq 24 \mathrm{~h}$ ischemic or hemorrhagic cerebrovascular event confirmed by a neurologist. Peripheral arterial disease was was defined as having a previous diagnosis of peripheral arterial disease (including carotid artery, subclavian artery, lower extremity arterial disease). Heart failure (HF) was having a previous diagnosis of HF or left ventricular ejection fraction (LVEF) $<50 \%$ on admission. Chronic kidney disease (CKD) was defined as an eGFR $<60 \mathrm{ml} / \mathrm{min} / 1.73 \mathrm{~m} 2$. The estimated glomerular filtration rate (eGFR) was calculated based on the Chronic Kidney Disease Epidemiology Collaboration creatinine equation ${ }^{[10]}$. Body mass index (BMI) was determined by dividing the patients' weight in kilograms by the square of the patients' height in meters.

\section{The endpoint}

The primary endpoint was a composite of MACE, which included all-cause death, cardiac death, nonfatal myocardial infarction (MI) and stroke after at least 2 year from discharge. The secondary endpoint was all-cause death and cardiac death. Predictors of longterm MACE were also analyzed, and comparisons between medical therapy and the PCl at each SYNTAX score risk stratification were performed.

\section{Statistical analysis}

Continuous data, expressed by mean \pm SD, and comparisons between between 2 groups were analyzed using the unpaired Student's $t$ test or Wilcoxon test, and comparisons of continuous variables among multiple groups were analyzed using 1-way analysis of variance. Categorical data, expressed by numbers and percentages, were compared using the chi-square test, or Fisher's exact test in cases with cell values $<5$. Kaplan-Meier method was adopted to estimate long -term outcomes among multiple groups and compared by the log-rank test. Cox proportional hazards regression used to identify MACE predictors, and all variables with a $P<0.1$ in the univariate analysis were used to carry out the multivariate analysis. A two-side $P<0.05$ was considered to be statistically significant. SPSS version 17.0 (SPSS, Chicago, IL,USA) was applied to conduct all analyses.

\section{Results}


Overall, 3,934 patients with UAP were included in this study, of which 1,570 patients were excluded: including 113 with prior CABG, 380 with prior $\mathrm{PCl}$ and 1,077 patients with missing data, finally, 2,364 patients were enrolled (Figure 1), including $1432(60.6 \%)$ men and 932 (39.4\%) women. The mean age was $64.92 \pm 9.84$ years (range: 28-90). In this study, 1,059 patients received medical therapy in-hospitalization, of which, 41 patients underwent PCl in follow-up period, finally, 1,018 (43.1\%) patients underwent medical therapy and 1,346 (56.9\%) patients underwent PCl (Figure 1).

\section{Difference in baseline characteristics among SYNTAX score groups}

In this study, the mean SYNTAX score was $17.53 \pm 10.61$ (range: 2-66), and 1,695 (71.7\%) patients had low SYNTAX score, 432 (18.3\%) patients had a medium SYNTAX score and 237 (10\%) patients had a high SYNTAX score. The baseline characteristics according to SYNTAX score risk stratification were presented in Table 1. The mean age, and prevalence of smoking, diabetes, previous MI, heart failure, and the mean level of FPG, LDL-C and Hs-CRP were significantly higher in patients with medium-and highSYNTAX score than those with low SYNTAX score (all $P<0.05$ ). There were no differences in hypertension, family history of CHD, prior stroke, peripheral arterial disease, atrial fibrillation, and the mean level of BMI, TG, TC and serum uric acid among patients with low- medium- and high-SYNTAX score (all $P<0.05$ ). No differences in baseline clinical characteristics were existed between patients with medium SYNTAX score and those with high SYNTAX score, apart from more male patients in high SYNTAX score $(P>$ 0.05,Table 1).

\section{$P C l$ versus medical therapy in baseline characteristics}

Compared to patients in medical therapy group, patients in $\mathrm{PCl}$ group had more cardiovascular risk factors and comorbidities: the frequencies of male patients, smoking, diabetes, previous myocardial infarction, and the level of FPG, triglyceride, total cholesterol, LDL-C, and serum uric acid were notably higher (all $P<0.05$ ). In contrast, the mean age, atrial fibrillation and the level of HDL-C in the $\mathrm{PCl}$ group were lower than in medical therapy group (all $P<0.05$ ). There were no differences in hypertension, family history of CHD, prior stroke, peripheral arterial disease, heart failure, CKD, the mean level of BMI between $\mathrm{PCl}$ group and medical therapy group (all $P$ $>0.05$, Table 2). The PCI group had higher incidence of medium- and high-SYNTAX score compared to medical therapy group ( $26.1 \%$ vs $8.0 \% ; 14.0 \%$ vs $4.7 \%, P<0.05$, Table 2 ).

\section{Comparisons of long-term MACE by SYNTAX score and treatment}

All patients were followed up for 2-6 years with the average of $3.38 \pm 0.99$ years. MACE occurred in 95 patients (4.0\%): 31 patients occurred non-cardiac death, 39 patients occurred cardiac death, 9 patients had acute non-fatal myocardial infarction and 16 patients had stroke.

In medical therapy group, the incidence of long-term MACE in patients with low-, medium- and high-SYNTAX score were $2.8 \%, 2.5 \%$, $16.7 \%$, and the all-cause mortality was $2.0 \%, 2.5 \%, 14.6 \%$, and the cardiac mortality was $0.8 \%, 1.2 \%, 14.6 \%$, respectively (Table 4 ). Kaplan-Meier analysis showed that long-term MACE, all-cause mortality and cardiac mortality in patients with high SYNTAX score was higher than those of low- and medium- SYNTAX score in medical therapy group (all $P<0.01$, Figure 2 A-C).

In PCl group, the incidence of long-term MACE in low-, medium- and high-SYNTAX score were $4.0 \%, 4.0 \%, 7.4 \%$, and the all-cause mortality was $2.6 \%, 2.6 \%, 6.9 \%$ and the cardiac mortality was $1.6 \%, 1.1 \%, 3.7 \%$, respectively. Kaplan-Meier analysis showed the allcause mortality in patients with high SYNTAX score was higher than those of low- and medium-SYNTAX score $(P<0.05$, Figure 3 B), while, no differences in long-term MACE and cardiac death were discovered among patients with low-, medium- and high-SYNTAX score in $\mathrm{PCl}$ group $(P>0.05$, Figure $3 \mathrm{~A}, \mathrm{C})$.

\section{Predictors for long-term MACE in both medical therapygroup and PCl group}

According to Cox proportional hazards models with both univariable and multivariable approaches, long-term predictors are shown in Table 4. This result revealed that advanced age (HR 1.529,95\% Cl 1.022 2.301; $P=0.045)$, diabetes mellitus $(\mathrm{HR} 1.533,95 \% \mathrm{Cl}$ 1.022 2.301; $P=0.039)$, heart failure (HR 5.082, 95\% Cl 3.153 8.191; $P<0.001)$, and SYNTAX score $\geq 33(\mathrm{HR} 2.171,95 \% \mathrm{Cl}$ 1.334 3.533; $P=0.002)$ were independent predictors for long-term MACE in the medical therapy group $(P<0.05)$, while, heart failure (HR 4.597, 95\% Cl 2.812 7.516; $P<0.001)$ and CKD (HR 2.815, 95\% Cl 1.773 4.470; $\mathrm{P}<0.001)$ were predictors of long-term MACE in PCl group, but not finding high SYNTAX score as a predictors for long-term MACE in PCl group $(P<0.05$, Table 3$)$. 
The overall MACE showed no difference between medical therapy group and PCI group $(P>0.05)$. According to SYNTAX score risk stratification, there were no difference in long-term MACE, all-cause mortality, cardiac death, nonfatal MI and stroke between medical therapy group and PCI group with low- and medium- SYNTAX score $(P>0.05)$. However, in patients with high SYNTAX score, patients in medical therapy group showed higher MACE and cardiac death than patients in $\mathrm{PCl}$ group $(P<0.05)$, whereas no differences in all-cause mortality, nonfatal $\mathrm{MI}$ and stroke were detected between medical therapy group and PCl group $(P>0.05$, Table 4).

\section{Discussion}

In this study, the main observation were these: (1) male, advanced age, smoking, diabetes, heart failure, CKD, FPG, LDL-C and Hs-CRP were positively correlated with SYNTAX score, (2) a high SYNTAX score was a predictors for long-term MACE in medical therapy group, not in $\mathrm{PCl}$ group, (3) compared to medical therapy group, $\mathrm{PCl}$ could decline significantly the long-term MACE in patients with high SYNTAX score, but not reduction in long-term MACE in patients with low- and medium- SYNTAX score.

A series of studies reported that aging, male, diabetes mellitus and impaired renal function

were independent predictors for high SYNTAX score ${ }^{[11-14]}$. Karadeniz $M$ showed that increased hs-CRP were one of the strong predictors of high SYNTAX score in ACS patients ${ }^{[15]}$. Minamisawa M reported high SYNTAX score was associated with heart failure ${ }^{[16]}$. In this study, we found the cardiovascular risk factors of patients with medium SYNTAX score are similar to those with high SYNTAX score, and male, advanced age, smoking, diabetes, heart failure, CKD, FPG, LDL-C and Hs-CRP were positively correlated with SYNTAX score, which were consistent with the above conclusion. Despite the pathogenesis between SYNTAX score and heart failure or CKD are not clear, this result suggested that high SYNTAX score may be related to systemic atherosclerosis. Therefore, intensive management of cardiovascular risk factors, especially for glucose, eGFR and Hs-CRP, was important to prevent coronary atherosclerosis.

Previous reports demonstrated that patients with high SYNTAX score had worse prognosis, moreover, studies using SYNTAX scores reported its capacity to predict adverse events for patients undergiong PCI and the prognostic value of the SYNTAX score in all cause mortality was also shown at different points in time up to five years after $\mathrm{PCl}{ }^{[17-20]}$. This study reached the same conclusion that MACE was higher in patients with high SYNTAX sore in both medical therapy group and PCl group. However, this study showed that a high SYNTAX score ( $\geq 33$ ) was an independent predictor for long-term MACE in the medical therapy group, but not in PCl group. This result maybe related to the advancement of coronary intervention technology and stent in recently years. In addition, advanced age, diabetes mellitus were independent predictors for long-term MACE in the medical therapy group, but not in $\mathrm{PCl}$ group, which indicated PCl could decline long- term MACE in high risk UAP patients. We also discovered that heart failure and CKD were independent predictors for long-term MACE in both medical therapy group and PCI group. Accordingly, intensive management should be made in patients with heart failure or CKD.

Compared to medical treatment, $\mathrm{PCl}$ could improve short-term and long-term prognosis of patients with CHD, and CABG was better than PCI in patients with high SYNTAX score ${ }^{[1-2]}$. Recently, BARI-2D Trial demonstrated, among patients with diabetes and stable ischemic heart disease, 5- year MACE were not lower after PCI than medical therapy in patients with a low- or mid/high- SYNTAX score $(17.8 \% \text { vs. } 19.2 \%, P=0.84 ; 35.6 \% \text { vs. } 26.5 \%, p=0.12)^{[21]}$. Moreover, Su CS et al reported that there was no difference in inhospital and long-term mortalities between $\mathrm{CABG}$ and $\mathrm{PCl}$ in patients with multivessel $\mathrm{CHD}{ }^{[22]}$. In thus study, we found that $\mathrm{PCl}$ showed an advantage in regard to long-term MACE and cardiac death in patients with a high SYTAX score, but not declining longterm MACE among either patients with a low- or medium- SYNTAX score. The result was inconsistent with the BARI-2D Trial, which may be that patients with stable coronary heart disease and type 2 diabetes mellitus were enrolled in the BARI-2D Trial, and it did not compare clinical outcomes in patients with a high SYNTAX score. This finding also suggested patients with high SYNTAX scores benefit more from coronary revascularization.

\section{Conclusions}

First, a high SYNTAX score was an predictor for long-term MACCE in medical therapy group, but not in PCl group. Second, PCl could reduce MACE and cardiac death significantly for patients with high SYNTAX score compared to medical therapy after at least 2-year 
from discharge.

\section{Study Limitations}

In our study, there were several limitations. First, this was a single-center, retrospective, observational study, and the result was less convincing than randomized controlled trials. Second, UAP patients received medical therapy or PCl were enrolled and patients undergoing coronary artery bypass grafting were not enrolled, so our findings may not be representative for these patients. Third, SYNTAX score are only risk stratification of anatomic features of coronary lesions and do not consider the degree of coronary stenosis and clinical factors, so patients with the same SYNTAX score may have different degrees of coronary stenosis, and the prognosis may be different. Finally, we focused on hard cardiac events in this study, so revascularization was not assessed as an outcome. Future studies should be carried out to examine these.

\section{Abbreviations}

CHD: coronary heart disease; UAP:Unstable Angina Pectoris; MI: myocardial infarction; BMI: Body mass index; HDL-C: Low density lipoprotein cholesterol-C; LDL-C: Low density lipoprotein cholesterol-C; eGFR: estimated Glomerular Filtration Rate; PCI: Percutaneous coronary intervention; MACE: major adverse cardiovascular events.

\section{Declarations}

\section{Acknowledgements}

We gratefully acknowledge the contributions of all staffs who work on the CBD-Bank.

\section{Authors' contributions}

MX performed study, statistical analysis and wrote manuscript. HC participated in study data collection. HWL contributed to the conception and design. All authors read and approved the final manuscript.

\section{Funding}

This research received no grant from any funding agency in the public, commercial, or not-for-profit sectors.

\section{Availability of data and materials}

The data used and/or analyzed during the current study are available from the corresponding author on reasonable request.

\section{Ethics approval and consent to participate}

This is a retrospective study, and the written informed consent was obtained from each participant on admission. This study was approved by the Institution Review Board of Beijing Friendship Hospital. All procedures performed in studies involving human participants were in accordance with the ethical standards of the institution and with the 1964 Helsinki Declaration and its later amendments or comparable ethical standards.

\section{Consent for publication}

Not applicable.

\section{Competing interests}

The authors declare that they have no conflict of interest.

\section{Author details}

${ }^{1}$ Department of Cardiology, Beijing Friendship Hospital, Capital Medical University, Beijing, China. ${ }^{2}$ Department of Geriatrics, Beijing Friendship Hospital, Capital Medical University, Beijing, China. 


\section{References}

1. Serruys PW, Morice MC, et al; SYNTAX Investigators. Percutaneous coronary intervention versus coronary-artery bypass grafting for severe coronary artery disease. N Engl J Med. 2009; 360(10):961-9

2. Mohr FW, Morice MC, Kappetein AP, et al. Coronary artery bypass graft surgery versus percutaneous coronary intervention in patients with three-vessel disease and left main coronary disease: 5-year follow-up of the randomised, clinical SYNTAX trial. Lancet. 2013; 381(9867): 629-6

3. Wallentin L. Implications of the FRISCII trial: initial medical stabilization followed by an early invasive approach is the preferred strategy in unstable coronary syndromes. Scand Cardiovasc J. 2000; 34(1):4-6.

4. Xia F, Jia D, Han Y, et al. Different Treatment Strategies for Patients with Multivessel Coronary Disease and High SYNTAX Score. Cell Biochem Biophys. 2015; 73(3):769-7

5. Liu S, Parr C, Zhang H, et al. Patient outcomes in GuideLiner facilitated percutaneous coronary intervention stratified by the SYNTAX score: A retrospective analysis. JRSM Cardiovasc Dis. 2019; 8:2048004019835449.

6. Waters DD, Arsenault BJ. Predicting Prognosis in Acute Coronary Syndromes: Makeover Time for TIMI and GRACE? Can J Cardiol. 2016; 32(11):1290-1293.

7. Bekler A, Altun B, Gazi E, et al. Comparison of the GRACE risk score and the TIMI risk index in predicting the extent and severity of coronary artery disease in patients with acute coronary syndrome. Anatol J Cardiol. 2015; 15(10):801-80

8. Roffi M, Patrono C, ESC Scientific Document Group et al. 2015 ESC Guidelines for the management of acute coronary syndromes in patients presenting without persistent ST-segment elevation: Task Force for the Management of Acute Coronary Syndromes in Patients Presenting without Persistent ST-Segment Elevation of the European Society of Cardiology (ESC). Eur Heart J. 2016; 37(3):267-315.

9. Bardin T, Richette P. Definition of hyperuricemia and gouty conditions. Curr Opin Rheumatol. 2014;26(2):186-91.

10. Filiopoulos V, Koutis I, Takouli L, et al. Chronic kidney disease epidemiology collaboration equation accuracy in predicting peritoneal dialysis-delivered creatinine clearance. Ren Fail. 2013;35(1):88-93.

11. Tanaka T, Seto S, Yamamoto K, et al. An assessment of risk factors for the complexity of coronary artery disease using the SYNTAX score Cardiovasc Interv Ther. 2013; 28(1): 16-21.

12. Aksakal E, Tanboga IH, Kurt M, et al. Predictors of coronary lesions complexity in patients with stable coronary artery disease. Angiology. 2013; 64(4):304-309.

13. Duran $\mathrm{M}$, Uysal OK, Gunebakmaz $\mathrm{O}$, et al. Glomerular filtration rate is associated with burden of coronary atherosclerosis in patients with acute coronary syndrome. Angiology. 2014; 65(4): 350-356.

14. Uçar H, Gür M, Seker T, et al. Impaired kidney function is associated with SYNTAX score in patients with stable coronary artery disease. Turk Kardiyol Dern Ars. 2014; 42(7):621-628.

15. Karadeniz M, Duran M, Akyel A, et al. High Sensitive CRP Level Is Associated With Intermediate and High Syntax Score in Patients With Acute Coronary Syndrome. Int Heart J. 2015; 56(4):377-3

16. Minamisawa M, Miura T, et al ; SHINANO Registry Investigators. Prediction of 1-year clinical outcomes using the SYNTAX score in patients with prior heart failure undergoing percutaneous coronary intervention: sub-analysis of the SHINANO registry. Heart Vessels. 2017; 32(4):399-407.

17. Bundhun PK, Bhurtu A, Huang F. Worse clinical outcomes following percutaneous coronary intervention with a high SYNTAX score: A systematic review and meta-analysis. Medicine (Baltimore). 2017; 96(24):e7140.

18. Brown AJ, McCormick LM, Gajendragadkar PR, et al. Initial SYNTAX score predicts major adverse cardiac events after primary percutaneous coronary intervention. Angiology. 2014; 65(5): 408-4

19. Eickhoff M, Schüpke S, Khandoga A, et al. Age-dependent impact of the SYNTAX-score on longer-term mortality after percutaneous coronary intervention in an all-comer population. J Geriatr Cardiol. 2018; 15(9):559-566.

20. Fuchs FC, Ribeiro JP, Fuchs FD, et al. Syntax Score and Major Adverse Cardiac Events in Patients with Suspected Coronary Artery Disease: Results from a Cohort Study in a University-Affiliated Hospital in Southern Brazil. Arq Bras Cardiol. 2016; 107(3):207-215. 
21. Ikeno F, Brooks MM, Nakagawa K, et al; BARI-2D Study Group. SYNTAX Score and Long-Term Outcomes: The BARI-2D Trial. J Am Coll Cardiol. 2017; 69(4):395-403.

22. Su CS, Shen $\mathrm{CH}$, Chang $\mathrm{KH}$, et al. Clinical outcomes of patients with multivessel coronary artery disease treated with robotassisted coronary artery bypass graft surgery versus one-stage percutaneous coronary intervention using drug-eluting stents. Medicine (Baltimore). 2019; 98(38):e17202.

\section{Tables}

Table 1 Baseline characteristics by SYNTAX score

\begin{tabular}{|c|c|c|c|c|}
\hline & $\begin{array}{l}\text { SYNTAX score } \\
\leq 22 \rrbracket N=1695 \rrbracket\end{array}$ & $\begin{array}{l}\text { SYNTAX score } \\
23-32(\mathrm{~N}=432)\end{array}$ & $\begin{array}{l}\text { SYNTAX score } \\
\geq 33 \llbracket N=237 \text { ) }\end{array}$ & $P$ value \\
\hline Age in years (mean, SD) & $64.50 \pm 9.72$ & $65.79 \pm 9.99$ a & $66.34 \pm 10.20 \mathrm{a}$ & 0.003 \\
\hline Male (n, \%) & $989(58.3)$ & $273(63.2)$ & 170 (71.7) a,b & 0.000 \\
\hline History of smoking (n, \%) & $779(46.0)$ & $226(52.3)$ a & $135(57.0)$ a & 0.001 \\
\hline Hypertension (n, \%) & $1225(72.3)$ & $325(75.2)$ & $171(72.2)$ & 0.454 \\
\hline Diabetes mellitus (n, \%) & $571(33.7)$ & $190(44.0)$ a & $115(48.5)$ a & 0.000 \\
\hline Family history of $\mathrm{CHD}(\mathrm{n}, \%)$ & $455(26.8)$ & $117(27.1)$ & $53(22.4)$ & 0.323 \\
\hline Previous MI (n, \%) & $104(6.1)$ & $53(12.3) a$ & $33(13.9)$ a & 0.000 \\
\hline Prior stroke $(\mathrm{n}, \%)$ & $265(15.6)$ & $73(16.9)$ & $45(19.0)$ & 0.385 \\
\hline Prior PAD (n, \%) & $129(7.6)$ & $34(7.9)$ & $27(11.4)$ & 0.132 \\
\hline Atrial fibrillation $(n, \%)$ & $98(5.8)$ & $22(5.1)$ & $8(3.4)$ & 0.293 \\
\hline Heart failure (n, \%) & $77(4.5)$ & $33(7.6) a$ & $23(9.7) a$ & 0.001 \\
\hline Chronic kidney disease & $164(9.7)$ & $60(13.9)$ & $39(16.5)$ & 0.001 \\
\hline BMI『kg/m2『 & $25.93 \pm 3.51$ & $25.77 \pm 3.53$ & $25.74 \pm 3.48$ & 0.563 \\
\hline $\mathrm{FPG}(\mathrm{mmol} / \mathrm{L})$ & $5.73 \pm 1.65$ & $6.25 \pm 2.27 \mathrm{a}$ & $6.53 \pm 2.14 \mathrm{a}$ & 0.000 \\
\hline Triglyceride『mmol/L】 & $1.63 \pm 1.15$ & $1.65 \pm 0.99$ & $1.65 \pm 1.13$ & 0.897 \\
\hline Total cholesterol (mmol/L) & $4.29 \pm 1.02$ & $4.41 \pm 1.14$ & $4.42 \pm 1.11$ & 0.050 \\
\hline HDL-C邓mmol/L》 & $1.15 \pm 0.28$ & $1.12 \pm 0.27$ & $1.12 \pm 0.25$ & 0.069 \\
\hline LDL-C $₫ \mathrm{mmol} / \mathrm{L} \rrbracket$ & $2.42 \pm 0.74$ & $2.51 \pm 0.81 \mathrm{a}$ & $2.54 \pm 0.79 a$ & 0.010 \\
\hline Serum uric acid囚umol/L】 & $339.56 \pm 82.94$ & $342.54 \pm 83.10$ & $345.81 \pm 88.26$ & 0.430 \\
\hline Hs-CRP & $3.26 \pm 5.46$ & $4.07 \pm 6.72 \mathrm{a}$ & $4.79 \pm 6.83 \mathrm{a}$ & 0.000 \\
\hline
\end{tabular}

a: compare with low SYNTAX score; b: compare with medium SYNTAX score, CHD = CORONARY HEART DISEASE; MI = myocardial infarction; $F P G=$ Fasting plasma glucose; $P A D=$ Peripheral arterial disease BMI= Body mass index; HDL-C = Low density lipoprotein cholesterol-C; LDL-C = Low density lipoprotein cholesterol-C; Hs-CRP = High-sensitivity C-Reactive Protein.

Table $2 \mathrm{PCl}$ versus medical therapy in baseline characteristics 


\begin{tabular}{|c|c|c|c|}
\hline & $\begin{array}{l}\text { Medical therapy group } \\
(\mathrm{n}=1,018 \rrbracket\end{array}$ & $\begin{array}{l}P C l \text { group } \\
(n=1,346)\end{array}$ & $P$ value \\
\hline Age in years & $65.6 \pm 9.6$ & $64.4 \pm 10.0$ & 0.003 \\
\hline male $(n, \%)$ & $562(55.2)$ & $870(64.6)$ & 0.000 \\
\hline History of smoking (n, \%) & $(43.4)$ & $698(51.9)$ & 0.000 \\
\hline Hypertension (n, \%) & $769(75.5)$ & $1004(74.6)$ & 0.598 \\
\hline Diabetes mellitus (n, \%) & $368(36.1)$ & $573(42.6)$ & 0.002 \\
\hline Family history of CHD (n, \%) & $270(26.5)$ & $355(26.4)$ & 0.936 \\
\hline Previous MI (n, \%) & $65(6.4)$ & $125(9.3)$ & 0.010 \\
\hline Prior stroke $(\mathrm{n}, \%)$ & $153(15.0)$ & $230(17.1)$ & 0.179 \\
\hline Peripheral arterial disease $(n, \%)$ & $77(7.6)$ & $113(8.4)$ & 0.462 \\
\hline Atrial fibrillation $(\mathrm{n}, \%)$ & $73(7.2)$ & $55(4.1)$ & 0.001 \\
\hline Heart failure (n, \%) & $55(5.4)$ & $78(5.8)$ & 0.682 \\
\hline Chronic kidney disease & $114(11.2)$ & $149(11.1)$ & 0.992 \\
\hline BMI『kg/m2】 & $25.84 \pm 3.57$ & $25.92 \pm 3.47$ & 0.577 \\
\hline Fasting plasma glucose (mmol/L) & $7.85 \pm 3.18$ & $8.38 \pm 3.94$ & 0.001 \\
\hline Triglyceride $\bigotimes \mathrm{mmol} / \mathrm{L} \rrbracket$ & $1.56 \pm 1.16$ & $1.68 \pm 1.09$ & 0.009 \\
\hline Total cholesterol (mmol/L) & $4.27 \pm 0.96$ & $4.37 \pm 1.11$ & 0.014 \\
\hline HDL-C『mmol/L】 & $1.17 \pm 0.27$ & $1.12 \pm 0.27$ & 0.000 \\
\hline LDL-C $₫ \mathrm{mmol} / \mathrm{L} \rrbracket$ & $2.39 \pm 0.70$ & $2.49 \pm 0.79$ & 0.001 \\
\hline Serum uric acid $₫$ umol/L】 & $335 \pm 85$ & $345 \pm 82$ & 0.006 \\
\hline SYNTAX score & $12.90 \pm 9.33$ & $21.04 \pm 10.16$ & 0.000 \\
\hline Low SYNTAX score $(\mathrm{n}, \%)$ & $889(87.3)$ & $806(59.9)$ & \multirow[t]{3}{*}{0.000} \\
\hline Medium SYNTAX score $(\mathrm{n}, \%)$ & $81(8.0)$ & $351(26.1)$ & \\
\hline High SYNTAX score $(\mathrm{n}, \%)$ & $48(4.7)$ & $189(14.0)$ & \\
\hline
\end{tabular}

MI: myocardial infarction; BMI: Body mass index; HDL-C: Low density lipoprotein cholesterol-C; LDL-C: Low density lipoprotein cholesterol-C; eGFR: estimated Glomerular Filtration Rate; PCI: Percutaneous coronary intervention.

Table 3. Predictors for long-term MACE in patients underwent medical therapy or PCI 


\begin{tabular}{|c|c|c|c|c|c|c|c|c|}
\hline & \multicolumn{4}{|l|}{ Medication group } & \multicolumn{4}{|l|}{$\mathrm{PCl}$ group } \\
\hline & \multicolumn{2}{|l|}{ Univariable analysis } & \multicolumn{2}{|c|}{ Multivariable analysis } & \multicolumn{2}{|c|}{ Univariable analysis } & \multicolumn{2}{|c|}{ Multivariable analysis } \\
\hline & $\mathrm{HR}(95 \% \mathrm{Cl})$ & $\begin{array}{l}P \\
\text { value }\end{array}$ & $\mathrm{HR}(95 \% \mathrm{Cl})$ & $\begin{array}{l}P \\
\text { value }\end{array}$ & $\mathrm{HR}(95 \% \mathrm{Cl})$ & $\begin{array}{l}P \\
\text { value }\end{array}$ & $\mathrm{HR}(95 \% \mathrm{Cl})$ & $\begin{array}{l}P \\
\text { value }\end{array}$ \\
\hline $\begin{array}{l}\text { Age in years } \\
>65\end{array}$ & $\begin{array}{l}2.625 \\
(1.038 \sim 6.638)\end{array}$ & 0.041 & $\begin{array}{l}1.529 \\
(1.022 \sim 2.301)\end{array}$ & 0.045 & $\begin{array}{l}0.853 \\
(0.477 \sim 1.526)\end{array}$ & 0.593 & & \\
\hline male & $\begin{array}{l}1.114 \\
(0.455 \sim 2.725)\end{array}$ & 0.813 & & & $\begin{array}{l}1.478 \\
(0.735 \sim 2.971)\end{array}$ & 0.273 & & \\
\hline $\begin{array}{l}\text { History of } \\
\text { smoking }\end{array}$ & $\begin{array}{l}0.819 \\
(0.329 \sim 1.997)\end{array}$ & 0.648 & & & $\begin{array}{l}0.752 \\
(0.406 \sim 1.392)\end{array}$ & 0.364 & & \\
\hline Hypertension & $\begin{array}{l}1.169 \\
(0.470 \sim 2.911)\end{array}$ & 0.737 & & & $\begin{array}{l}0.876 \\
(0.472 \sim 1.625)\end{array}$ & 0.674 & & \\
\hline $\begin{array}{l}\text { Diabetes } \\
\text { mellitus }\end{array}$ & $\begin{array}{l}3.267 \\
(1.569 \sim 6.800)\end{array}$ & 0.002 & $\begin{array}{l}1.533 \\
(1.022 \sim 2.301)\end{array}$ & 0.039 & $\begin{array}{l}1.006 \\
(0.593 \sim 1.705)\end{array}$ & 0.984 & & \\
\hline Hyperlipidemia & $\begin{array}{l}0.866 \\
(0.426 \sim 1.759)\end{array}$ & 0.690 & & & $\begin{array}{l}0.688 \\
(0.392 \sim 1.209)\end{array}$ & 0.194 & & \\
\hline $\begin{array}{l}\text { Family history } \\
\text { of CHD }\end{array}$ & $\begin{array}{l}1.122 \\
(0.484 \sim 2.600)\end{array}$ & 0.789 & & & $\begin{array}{l}1.099 \\
(0.598 \sim 2.020)\end{array}$ & 0.760 & & \\
\hline Hyperuricemia & $\begin{array}{l}0.388 \\
(0.135 \sim 1.111)\end{array}$ & 0.078 & & & $\begin{array}{l}0.905 \\
(0.479 \sim 1.710)\end{array}$ & 0.759 & & \\
\hline Previous Ml & $0.727(0.198 \sim 2.677)$ & 0.632 & & & $\begin{array}{l}1.371 \\
(0.647 \sim 2.904)\end{array}$ & 0.411 & & \\
\hline Prior stroke & $\begin{array}{l}1.033 \\
(0.424 \sim 2.521)\end{array}$ & 0.943 & & & $\begin{array}{l}1.746 \\
(0.953 \sim 3.200)\end{array}$ & 0.071 & & \\
\hline $\begin{array}{l}\text { Peripheral } \\
\text { arterial } \\
\text { disease }\end{array}$ & $\begin{array}{l}1.832 \\
(0.669 \sim 5.021)\end{array}$ & 0.239 & & & $\begin{array}{l}0.777 \\
(0.299 \sim 2.019)\end{array}$ & 0.604 & & \\
\hline $\begin{array}{l}\text { Atrial } \\
\text { fibrillation }\end{array}$ & $\begin{array}{l}2.023 \\
(0.728 \sim 5.623)\end{array}$ & 0.177 & & & $\begin{array}{l}1.792 \\
(0.696 \sim 4.613)\end{array}$ & 0.226 & & \\
\hline Heart failure & $\begin{array}{l}3.691 \\
(1.304 \sim 10.447)\end{array}$ & 0.014 & $\begin{array}{l}5.082 \\
(3.153 \sim 8.191)\end{array}$ & 0.000 & $\begin{array}{l}3.791 \\
(1.892 \sim 7.598)\end{array}$ & 0.000 & $\begin{array}{l}4.597 \\
(2.812 \sim 7.516)\end{array}$ & 0.000 \\
\hline $\begin{array}{l}\text { Chronic kidney } \\
\text { disease }\end{array}$ & $\begin{array}{l}1.654 \\
(0.692 \sim 3.954)\end{array}$ & 0.258 & & & $\begin{array}{l}3.001 \\
(1.570 \sim 5.738)\end{array}$ & 0.001 & $\begin{array}{l}2.815 \\
(1.773 \sim 4.470)\end{array}$ & 0.000 \\
\hline SYNTAX $\geq 33$ & $\begin{array}{l}6.495 \\
(2.705 \sim 15.595)\end{array}$ & 0.000 & $\begin{array}{l}2.171 \\
(1.334 \sim 3.533)\end{array}$ & 0.002 & $\begin{array}{l}1.481 \\
(0.793 \sim 2.767)\end{array}$ & 0.218 & & \\
\hline BMI & $\begin{array}{l}0.950 \\
(0.856 \sim 1.054)\end{array}$ & 0.330 & & & $\begin{array}{l}1.013 \\
(0.981 \sim 1.047)\end{array}$ & 0.420 & & \\
\hline HS-CRP & $\begin{array}{l}1.030 \\
(0.993 \sim 1.068)\end{array}$ & 0.112 & & & $\begin{array}{l}1.015 \\
(0.983 \sim 1.049)\end{array}$ & 0.354 & & \\
\hline
\end{tabular}

MI: myocardial infarction; CHD: coronary heart disease, eGFR: estimated glomerular filtration rate; $\mathrm{PCl}=$ Percutaneous coronary intervention

$\mathrm{BMI}=$ Body mass index;

Table 4 PCl versus medical therapy in long-term MACE according to SYNTAX score 


\begin{tabular}{|c|c|c|c|c|c|c|c|c|c|c|c|c|}
\hline & \multicolumn{3}{|l|}{ Overall } & \multicolumn{3}{|c|}{ SYNTAX score $\leq 22$} & \multicolumn{3}{|c|}{ SYNTAX score $23-32$} & \multicolumn{3}{|c|}{ SYNTAX score $\geq 33$} \\
\hline & $\begin{array}{l}\text { Medical } \\
\text { therapy } \\
((\mathrm{n} \\
=1,018)\end{array}$ & $\begin{array}{l}\mathrm{PCl} \\
(\mathrm{n}= \\
1,346)\end{array}$ & $\begin{array}{l}P \\
\text { value }\end{array}$ & $\begin{array}{l}\text { Medical } \\
\text { therapy } \\
(n= \\
889 \square\end{array}$ & $\begin{array}{l}\mathrm{PCl} \\
(\mathrm{n}= \\
806)\end{array}$ & $\begin{array}{l}P \\
\text { value }\end{array}$ & $\begin{array}{l}\text { Medical } \\
\text { therapy } \\
(\mathrm{n}= \\
81)\end{array}$ & $\begin{array}{l}\mathrm{PCl} \\
(\mathrm{n}= \\
351)\end{array}$ & $\begin{array}{l}P \\
\text { value }\end{array}$ & $\begin{array}{l}\text { Medical } \\
\text { therapy } \\
(n=48)\end{array}$ & $\begin{array}{l}\mathrm{PCl} \\
(\mathrm{n}= \\
189)\end{array}$ & $\begin{array}{l}P \\
\text { value }\end{array}$ \\
\hline $\begin{array}{l}\text { MACE }(n, \\
\%)\end{array}$ & $35(3.4)$ & $\begin{array}{l}60 \\
(4.5)\end{array}$ & 0.211 & $25(2.8)$ & $\begin{array}{l}32 \\
(4.0)\end{array}$ & 0.187 & $2(2.5)$ & $\begin{array}{l}14 \\
(4.0)\end{array}$ & 0.514 & $8(16.7)$ & $\begin{array}{l}14 \\
(7.4)\end{array}$ & 0.048 \\
\hline $\begin{array}{l}\text { All-cause } \\
\text { death ( } n \text {, } \\
\%)\end{array}$ & $27(2.7)$ & $\begin{array}{l}43 \\
(3.2)\end{array}$ & 0.411 & $18(2.0)$ & $\begin{array}{l}21 \\
(2.6)\end{array}$ & 0.426 & $2(2.5)$ & $\begin{array}{l}9 \\
(2.6)\end{array}$ & 0.961 & $7(14.6)$ & $\begin{array}{l}13 \\
(6.9)\end{array}$ & 0.086 \\
\hline $\begin{array}{l}\text { Cardiac } \\
\text { death } \\
(n, \%)\end{array}$ & $13(1.3)$ & $24(1.8)$ & 0.326 & $7(0.8)$ & $\begin{array}{l}13 \\
(1.6)\end{array}$ & 0.116 & $1(1.2)$ & $\begin{array}{l}4 \\
(1.1)\end{array}$ & 0.943 & $7(14.6)$ & $\begin{array}{l}7 \\
(3.7)\end{array}$ & 0.004 \\
\hline $\begin{array}{l}\text { Nonfatal } \\
\operatorname{MI}(n, \%)\end{array}$ & $3(0.3)$ & $6(0.4)$ & 0.555 & $2(0.2)$ & $\begin{array}{l}3 \\
(0.4)\end{array}$ & 0.557 & $0(0)$ & $\begin{array}{l}2 \\
(0.6)\end{array}$ & 0.496 & $1(2.1)$ & $\begin{array}{l}1 \\
(0.5)\end{array}$ & 0.293 \\
\hline $\begin{array}{l}\text { Stroke }(n, \\
\%)\end{array}$ & $5(0.5)$ & $\begin{array}{l}11 \\
(0.8)\end{array}$ & 0.338 & $5(0.6)$ & $\begin{array}{l}8 \\
(1.0)\end{array}$ & 0.311 & $0(0)$ & $\begin{array}{l}3 \\
(0.9)\end{array}$ & 0.404 & $0(0)$ & $0(0)$ & \\
\hline
\end{tabular}

\section{Figures}

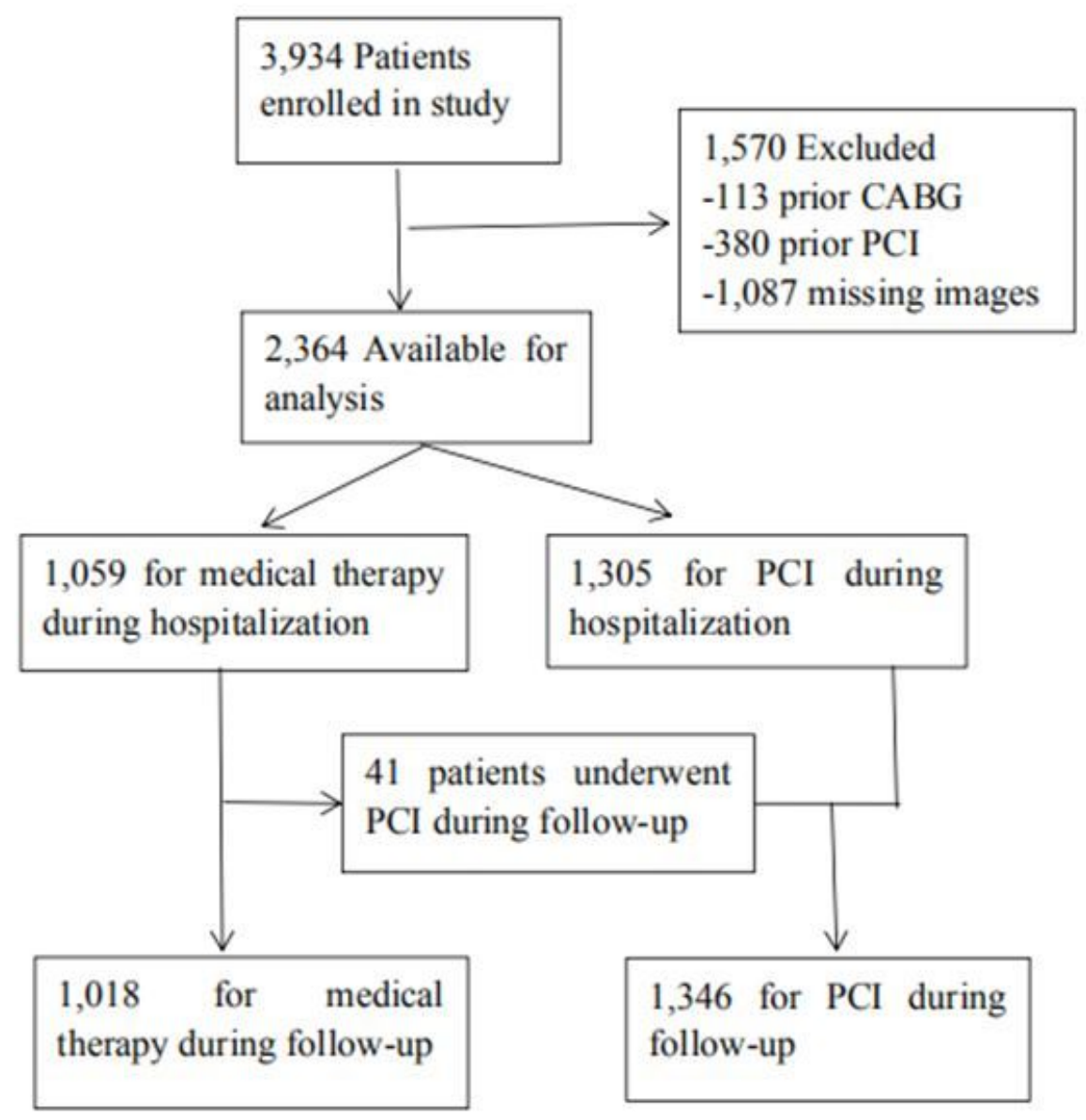

\section{Figure 1}

Study design 
$\mathbf{A}$
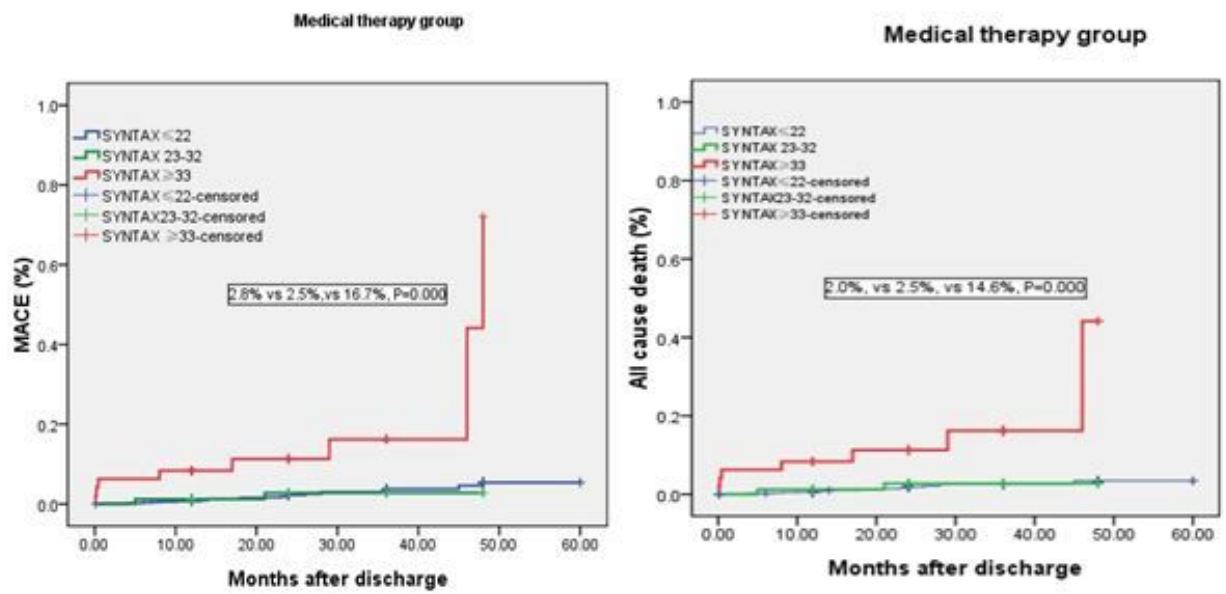

C

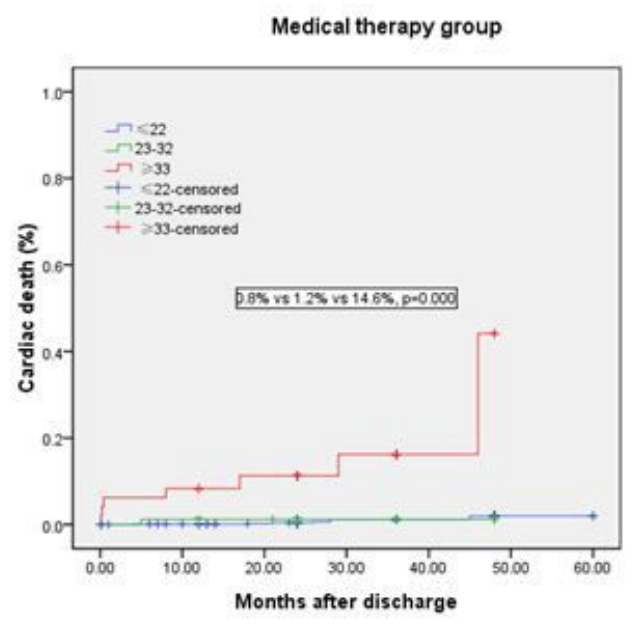

Figure 2

Comparison of MACE among SYNTAX Score in medical therapy group 
$\mathbf{A}$

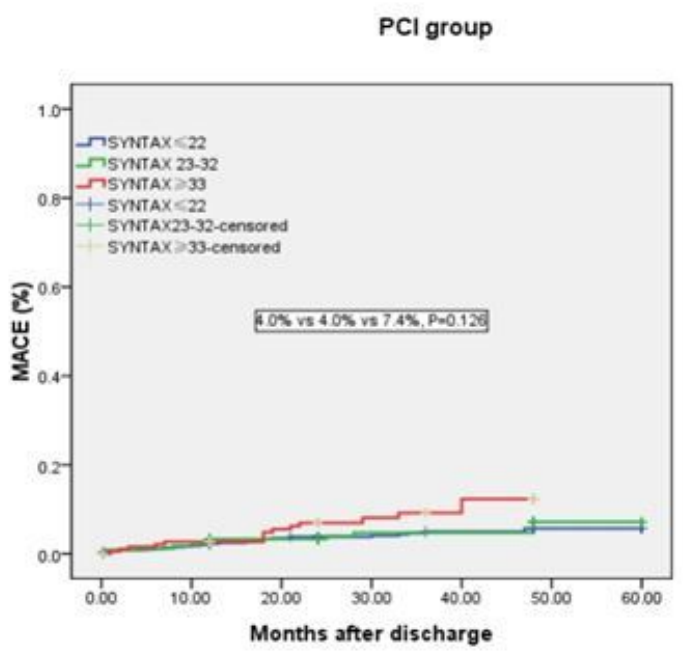

C

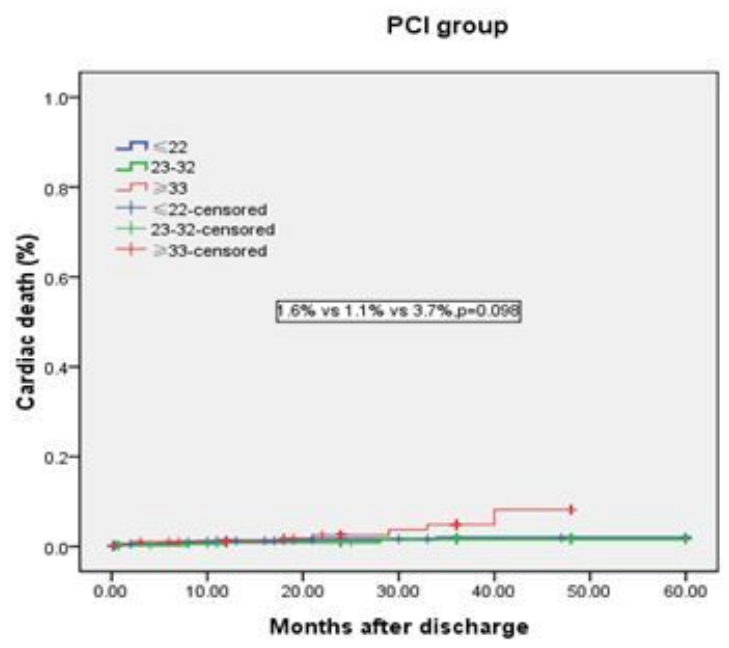

Figure 3

Comparison of MACE among SYNTAX Score in PCl group
B

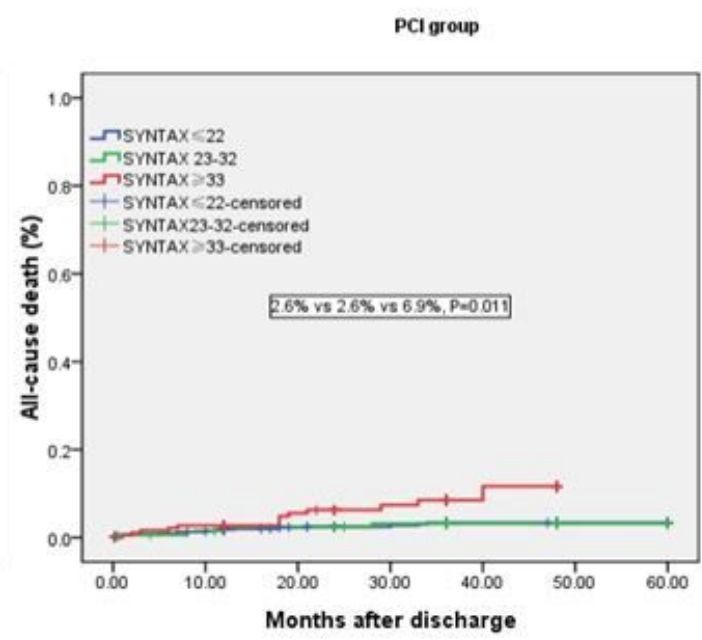

